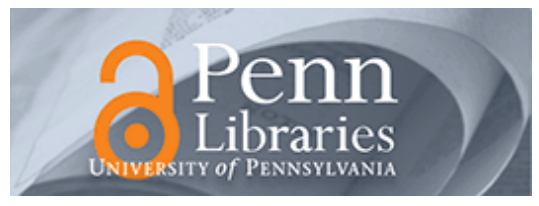

University of Pennsylvania ScholarlyCommons

November 2008

\title{
Developing Academic Strategic Alliances: Reconciling Multiple Institutional Cultures, Policies, and Practices
}

Peter D. Eckel

American Council on Education

Matthew Hartley

University of Pennsylvania, hartley@gse.upenn.edu

Follow this and additional works at: https://repository.upenn.edu/gse_pubs

\section{Recommended Citation}

Eckel, P. D., \& Hartley, M. (2008). Developing Academic Strategic Alliances: Reconciling Multiple

Institutional Cultures, Policies, and Practices. Retrieved from https://repository.upenn.edu/gse_pubs/187

Copyright (C) 2008 by The Ohio State University. Reprinted with permission. Reprinted from Journal of Higher Education, Volume 79, Issue 6, November/December 2008, pages 613-637.

Publisher URL: http://muse.jhu.edu/journals/jhe/

This paper is posted at ScholarlyCommons. https://repository.upenn.edu/gse_pubs/187

For more information, please contact repository@pobox.upenn.edu. 


\title{
Developing Academic Strategic Alliances: Reconciling Multiple Institutional Cultures, Policies, and Practices
}

\author{
Abstract \\ Colleges and universities have often been required to evolve in response to shifting societal priorities. \\ Over the past century, this occurred in the context of an ever-expanding system of higher education built \\ with a substantial investment of public money. If society needed more professional programs, institutions \\ added them. In the current context, however, the expectation of institutional accountability remains \\ undiminished despite an increasingly resource-constrained environment. This places colleges and \\ universities in a double bind. They are expected to address society's needs, yet they often do not have the \\ resources to respond to them. Our institutions of higher learning are limited in the ways they can generate \\ additional capital, and efforts to free resources by reducing administrative overhead and reallocating \\ responsibilities have often produced pyrrhic victories (Eckel, 2003).

\section{Comments} \\ Copyright ( $\odot 2008$ by The Ohio State University. Reprinted with permission. Reprinted from Journal of \\ Higher Education, Volume 79, Issue 6, November/December 2008, pages 613-637. \\ Publisher URL: http://muse.jhu.edu/journals/jhe/
}




\section{\#E Peter D. Eckel}

\section{Developing Academic Strategic Alliances: Reconciling Multiple Institutional Cultures, Policies, and Practices}

\section{The Promise of Interinstitutional Collaboration}

Colleges and universities have often been required to evolve in response to shifting societal priorities. Over the past century, this occurred in the context of an ever-expanding system of higher education built with a substantial investment of public money. If society needed more professional programs, institutions added them. In the current context, however, the expectation of institutional accountability remains undiminished despite an increasingly resource-constrained environment. This places colleges and universities in a double bind. They are expected to address society's needs, yet they often do not have the resources to respond to them. Our institutions of higher learning are limited in the ways they can generate additional capital, and efforts to free resources by reducing administrative overhead and reallocating responsibilities have often produced pyrrhic victories (Eckel, 2003).

The research for this paper was conducted under the auspices of the American Council on Education (ACE)'s Changing Enterprise Project (http://www.acenet.edu/ programs/change-enterprise), which was supported by contributions from Accenture, The Goldman Sachs Foundation, and Peterson's, a Thomson Learning Company. The authors thank Christopher Morphew and three anonymous reviewers for their helpful comments on previous drafts.

Peter Eckel is Director, Programs and Initiatives, in the Center for Effective Leadership at the American Council on Education, One Dupont Circle, NW, Washington, D.C. 20036 (Peter_Eckel@ace.nche.edu). Matthew Hartley is Assistant Professor at the Graduate School of Education, University of Pennsylvania (Hartley@gse.upenn.edu).

The Journal of Higher Education, Vol. 79, No. 6 (November/December 2008) Copyright $(\odot 2008$ by The Ohio State University 
However, one promising means for developing new capacities is the creation of strategic partnerships between colleges and universities. Such arrangements are well documented in the management literature. Termed interorganizational relationships (IORs), such collaborative enterprises assume a variety of forms (Bailey \& McNally Koney, 2000; Barringer \& Harrison, 2000). They may be differentiated from one another on a number of dimensions, including: (a) the financial support contributed by each partner, (b) the extent to which the organizational and/or governance structure is formalized and centralized, and (c) the relative contribution of each partner in the development and production of a given good or service. In this study, we focus on academic IORs that are strategic in nature (i.e., they extend beyond the mere sharing of library books or bulk purchasing or similar consortia activities) and have been "established for a variety of reasons relating to the inability of one of the partners to solve an important problem" (Borys \& Jemison, 1989, p. 241). To put it simply, they are working together because no single partner can accomplish what it seeks on its own.

The management literature on strategic alliances points out that they are formed for a variety of reasons (Gulati \& Singh, 1998) and notes that the rationales for holding them together may shift over time (Spekman, Forbes, Isabella, \& MacAvoy, 1998). Alliances open doors to markets by pooling financial and human resources, thereby producing new combinations of products, services, and expertise (Bailey \& McNally Koney, 2000; Gulati \& Singh, 1998; Hagadoorn, 1993; Oliver, 1990). They extend capabilities, improve the delivery of services, generate greater economies of scale, and reduce expenses by linking complementary technologies or sharing facilities and capacities and jointly investing in new innovations, such as technology (Bailey \& McNally Koney, 2000; Borys \& Jemison, 1989; Gulati \& Singh, 1998; Hagadoorn, 1993; Whetten, 1981). Alliances have been shown to facilitate the development of new ideas and products and allow participating organizations to "leapfrog" into new areas (Gulati \& Singh, 1998; Hagadoorn, 1993). Partners that join together learn from one another (Doz, 1996; Hagadoorn, 1993), which is an advantage since buying knowledge and expertise in the marketplace can be prohibitively expensive (Barringer \& Harrison, 2000). Together, organizations may find it easier to monitor the changing environment and better understand emerging opportunities or risks (Gulati \& Singh, 1998; Hagadoorn, 1993). Alliances may also be formed to defend a current strategic position (Barringer \& Harrison, 2000). Finally, an organization may join an alliance to gain legitimacy through association with others, particularly larger, visible, reputable, and prestigious firms (Bailey \& McNally Koney, 2000; Barringer \& Harrison, 2000). 
However, managing IORs in the private sector has proven remarkably challenging. Park and Russo (1996) cite a series of studies that put the failure rate of strategic corporate alliances at 7 in 10, 2 in 3, and 1 in 2. This uneven history of success points to two principal challenges. First, a successful alliance requires participants to reconcile their organizational goals and to develop clear and compatible expectations (Doz, 1996). This is easier said than done, however, because not only do partners enter the alliance for different reasons, they often harbor divergent objectives (e.g., one may wish to expand market share while the other is interested in maximizing revenues). The absence of shared assumptions can make reconciling such differences challenging (Borys \& Jemison, 1989). Second, partners may have different organizational norms about decision making (Rondinelli \& London, 2001) — their operating procedures, policies, and governance structures (Borys \& Jemison, 1989; Saxton, 1997) and their accepted means of establishing trust (Ring \& Van de Ven, 1994) may therefore be difficult to reconcile. In a real sense, the central challenge of IORs is addressing disparate sets of values and assumptions - that is, reconciling organizational cultures.

\section{Academic Alliances}

Colleges and universities have a long history of collaborating (Martin \& Samels, 2002; Whealler Johnson \& Noftsinger, 2004) through consortia and exchange agreements, shared resources, coordinated curricula (such as $2+3$ programs and articulation agreements), athletic conferences, and joint research. These traditional partnerships differ in important ways from the interinstitutional programs in this study. The first tend to be operational in nature, more concerned with efficiencies (doing things better or cheaper) than with effectiveness (creating new activities in response to a changing environment; Pfeffer \& Salancik, 1978). They extend and enhance the existing capacities of the partners. Sharing library resources, joint purchasing, or cross-enrollments of students exemplify these kinds of arrangements (Dotolo \& Strandness, 1999).

This research focuses on a particular type of strategic alliance, what we call curricular joint ventures (CJVs; Eckel, Hartley, Affolter-Caine, 2004), which are partnerships where two or more institutions collaborate with one another-including making shared financial investments (thus assuming shared financial risks) — to develop an academic venture neither partner could launch on its own (Dussauge \& Garrette, 1999; Hamel, 1996; Porter, 1996). ${ }^{1}$ Although there are an increasing number of examples, higher-education alliances have been inadequately studied, especially curricular alliances. Further, what little has been written tends 
to be speculative and anecdotal (see, e.g., Dotolo \& Strandness, 1999; Martin \& Samels, 2002; Whealler Johnson \& Noftsinger, 2004). In this qualitative study, we gathered data from several existing CJVs to begin identifying the factors that influenced their formation and management. We pursued the following questions: How do institutions create mutually beneficial curricular joint ventures despite differences in institutional cultures, policies, and practices? How do alliances address inevitable conflicts and differences among the parent organizations?

\section{Using the Rules of Organizational Culture}

Effective academic strategic alliances depend on partners' ability not only to regularize processes and procedures but also to understand and reconcile multiple sets of norms and expectations (Borys \& Jemison, 1989; Rondinelli \& London, 2001; Saxton, 1997). We therefore have drawn from the literature on organizational culture to examine the factors that influence these partnerships. Organizational culture is "the deeply embedded patterns of organizational behavior and the shared values, assumptions, beliefs, or ideologies that members have about their organization or its work" (Peterson \& Spencer, 1991, p. 142) that reflect the key assumptions, understandings, and rules that govern daily behavior (Deal \& Kennedy, 1982). An organization's culture can be conceptualized as three interrelated levels (Schein, 1992). At its deepest level, culture consists of the underlying assumptions (often implicit and unstated) that guide behaviors. Culture becomes discernible in part through espoused values - the beliefs and priorities of people in a particular institutional context. ${ }^{2}$ Finally, most evident are the artifacts of culture-policy documents, mission statements, and so forth (Schein, 1992).

For this study, we adopted a social rules system framework (Burns \& Flam, 1987; March, 1994) to unearth operating cultural norms by documenting the formal and informal "rules" embedded in organizational life. Social rule systems theory holds that members of organizations develop rules for regularizing their work and mitigating confusion and conflict. The scaffolding of such rules reveals a great deal about shared norms and values, that is, organizational culture. Social rules significantly influence people's expectations about participating in decision making, establish participant obligations and rights, set parameters for work activities, and act as a guide to determine feasible outcomes (Burns \& Flam, 1987; March, 1994; March, Schulz, \& Zhou, 2000). Rules may be the expression of past political solutions (the agreements from negotiations between organization actors) or technical solutions 
(guidelines regarding what procedures seem to work). They may be either formal or informal (Burns \& Flam, 1987). Formal rules are found in policy guidelines or memoranda of understanding and are readily accessible cultural artifacts (Schein, 1992). Other rules, however, are implicitly understood as "the way we do things around here." These rules (and the underlying assumptions that guide them [Schein, 1992]) are obscured until a decision reveals them.

Identifying rules that guide behavior is an effective strategy for gaining insights into the beliefs, assumptions, and norms of institutional members (Helms Mills \& Mills, 2000). Organizational culture, from this perspective, is "primarily composed of a particular configuration of 'rules' enactment and resistance" (Mills, 1988, p. 366). CJV development offers particularly rich opportunities to observe rule making and rule following since partners must reconcile the dominant and accepted rules of operation of at least two organizations (Doz, 1996). As strategic alliances form, partners construct a common set of rules in two ways. First, prospective partners may begin by applying the rules from their individual organizational "rule pool" (March, 1994) to the new situation (Doz, 1996). Negotiation is the inevitable result because the rules each partner brings to the alliance reflect the disparate learning and histories of each institution (March, Schulz, \& Zhou, 2000). Second, the alliance must create new rules to address the unique situations created by the nascent collaboration. Rules are thus the result of problem solving, political negotiation, experiential learning, and diffusion (March, Schulz, \& Zhou, 2000) that in alliances occur both collectively and prior to the partnership.

It is this second set of rules that are of particular interest here. These rules require what Ronald Heifetz (1994) calls adaptive (as opposed to technical) responses. The real work for institutional leaders, he argues, is responding to adaptive challenges where no technical or tested solution exists. In the following analysis, we make no attempt to address the vast majority of CJV rules, which address basic operations because they tend to be based on the structure and nature of each alliance and, more important, are of little utility in understanding the core challenge facing these alliances-reconciling disparate organizational cultures and perceptions of purpose. Our intent is to focus on the development of rules that reconcile the organizational values and cultural assumptions of the partners.

\section{Methodology}

We employed a comparative case study methodology, focusing on a contemporary, real-life phenomenon (Yin, 1994) and drawing insights from the cases we developed on each CJV (Herriott \& Firestone, 1983). 


\section{Site Selection and Data Collection}

We selected three CJVs that represented common IOR structures to maximize variation (Patton, 1990): (a) a dyad (Virginia Tech-Wake Forest University School of Biomedical Engineering and Sciences [SBES]); (b) a medium-sized network of 5 institutions (OneMBA); and (c) a large network of 10 institutions (Great Plains Interactive Distance Education Alliance [Great Plains IDEA]). Single shared programs are provided by SBES and OneMBA, and Great Plains IDEA offers multiple degree programs from a single collaborative structure. We also identified CJVs that were serving increasing numbers of students and were financially viable. On these dimensions at least, the CJVs were successful.

From each CJV we identified: (a) the current leaders of the effort, (b) the individuals from each institution responsible for initiating that partner's involvement in the CJV, and (c) faculty who participate in the academic activities related to the venture. We also engaged in snowball or network sampling by following up with names of individuals provided by the primary contact (Patton, 1990). Ultimately, we conducted between 7 and 15 interviews for each CJV for a total of 30 interviews. We concluded interviewing respondents for each site when we reached data saturation (Glaser \& Strauss, 1967) and the redundancy of information from additional respondents yielded no new information. We also requested documents prior to the interviews such as meeting agendas, minutes of meetings, Web pages, handbooks, white papers, and reports. In addition, we observed one executive board planning retreat and conducted site visits to two campus partners. Because the CJVs studied spanned numerous organizations (and sometimes crossed national boundaries), we conducted many of the individual interviews by phone. All interviews were semistructured and aimed to elicit from participants their individual perspectives about their own roles in the formation and maintenance of the CJV (Rubin \& Rubin, 1995). The protocol consisted of open-ended questions (Yin, 1994), although we also used the "overlap method," seeking multiple perspectives on particularly important issues and events that emerged (Lincoln \& Guba, 1985). The interviews were tape recorded. We transcribed interviews verbatim for two cases and created interview $\log$ s for the third case.

\section{Data Analysis}

We drafted case reports or written condensations of all the data collected (approximately 60 pages each) for each CJV that included all of the potentially relevant material collected from the participating sites (Yin, 1994). The case reports allowed us to put into chronological order all of the information from each site to facilitate coding, identify gaps in 
the process, and look for points of convergence and divergence within the data to piece together the story of CJV development. They allowed us to identify points of high convergence in the data, highlight inconsistencies, and minimize unnecessary redundancy. We then pattern coded each case, looking to identify adaptive rules (Heifetz, 1994). Within the cases, we looked both for formal or explicit rules and for informal or implicit rules for each area. The formal rules predominately came from written documents, such as handbooks and policy statements, but also through the interviews. Implicit, informal rules surfaced when conflict arose between partners or between the alliance and individual institutions (March, 1994). Most of these were identified through the interviews. However, often new rules pointed to conflicts resolved.

Finally, we conducted a cross-case analysis. Independently, each researcher drafted rule memos from two of the cases (OneMBA and Great Plains IDEA) that pulled identified rules into a thematic cluster across the cases, and together we developed a set of propositions (Miles \& Huberman, 1994) regarding cultural, adaptive rules in CJVs from those two cases. We used the third case, SBES, as a means to further refine the initial propositions.

The research questions led to findings best described in terms of patterns and themes rather than confirmed hypotheses and explanations that were tested against common sense and plausibility rather than against predictive theories, both of which are common in the organization case study method (Pettigrew, 1995).

\section{Rigor and Limitations}

We adhered to Yin's (1994) three principles of rigor for case study research: (a) the use of multiple sources of evidence, (b) the construction of a database of information or case report specifically for the case study, and (c) the development of a logical chain of evidence describing the rationale and the processes used that connects the findings to the collected data.

Any study is bound to have limitations; it is what makes the study manageable (LeCompte \& Preissle, 1993). One limitation is the number of cases in this study. We identified three different types of alliances that involved research universities. Although the alliances are different, they are by no means representative of the possible approaches to curricular alliances, particularly to those pursued by other types of institutions such as liberal arts colleges or community colleges. A second limitation is the potential for participant biases and misperceptions common in organizational research (Van Maanen, 1979). Some of the participants in our study were heavily invested in the alliance and actively working to 
make it succeed. No doubt this colored their perspectives on the initiative. However, others (e.g., some faculty members and recently hired administrators) were less so. Asking participants to reflect on their own activities rather than simply having them speak generally about the overall enterprise and identifying people with different roles within the CJV provided a broader range of perspectives than we would have had had we conducted elite interviews (Holstein \& Gubrium, 1995). Although individual accounts may have been somewhat biased, we mitigated this by eliciting information from multiple participants in the CJV. Finally, the documents we reviewed were not produced for research purposes. Thus, they cannot be taken as literal recordings of events because they had other purposes than a desire to objectively inform such as persuasion or creating a commitment to action (Merriam, 1988).

An Overview of Three CJVs

\section{Virginia Tech-Wake Forest University School of Biomedical Engineering and Sciences (SBES)}

The SBES institution is a single graduate school jointly operated by a public land-grant university and a private university located in different states. This improbable partnership combines Virginia Tech's strengths in engineering with Wake Forest's medical school. The graduate programs at SBES offer students M.S. and Ph.D. degrees in biomedical engineering, a joint M.D./Ph.D. through the WFU School of Medicine, and a joint D.V.M./Ph.D. program through the Virginia-Maryland Regional College of Veterinary Medicine. Students designate a home campus in either Blacksburg, Virginia, or Winston-Salem, North Carolina. The school's first cohort included 30 graduate students from both institutions, half of whom were doctoral students. Approximately two-thirds were enrolled through Virginia Tech and the rest from Wake Forest. Currently, the curriculum is comprised of existing courses offered by each institution and new courses developed specifically for SBES. Because the institutions are a two hours' drive apart, some courses are taught via distance learning. The core faculty of SBES consists of 20 professors from Virginia Tech and 10 from Wake Forest, with more than 60 faculty affiliates. Five additional faculty members, whose primary appointment will be at SBES, are being hired. The collaboration promotes interinstitutional faculty research, linking faculty from medicine and engineering. A primary goal of the partnership (along with the joint degree program) is to be able to compete more effectively for National Institutes of Health $(\mathrm{NIH})$ grants by drawing upon the strengths of faculty from the 
two disciplines. The day-to-day administration of SBES is undertaken by its director and associate director (one from each campus). They report to a governing board, which provides oversight of the program and approves school policy. The board consists of eight voting members divided equally between the two institutions. The deans of several schools (e.g., the graduate school, college of engineering, school of medicine) serve as permanent members of the board, by virtue of their positions. Department chairs rotate annually to fill the remaining slots.

\section{OneMBA}

The OneMBA venture is a 21-month executive MBA program (its inaugural class began in fall 2002) that was created to deliver an internationally focused MBA program to executives of multinational corporations. Partners include the Kenan-Flagler Business School of the University of North Carolina, Chapel Hill (UNC); the Rotterdam School of Management (RSM) of Erasmus University Rotterdam; the Chinese University of Hong Kong (CUHK); the Monterrey Tech Graduate School of Business Administration and Leadership (EGADE) in Mexico; and Brazil's Escola de Administração de Empresas de São Paulo_the largest of the schools that make up the Fundação Getulio Vargas (FGV). The OneMBA program is a globally focused executive MBA program that each partner realized it could not independently deliver with the same international depth. Only through collaboration across national borders, the principals thought, could they provide a real-life (as opposed to "academic") experience for graduate business students seeking a global experience. Students enroll at one of the partner institutions and pay that institution's tuition and fees. The curriculum includes three components: (a) a series of courses taught by the student's home institution, (b) a "global residency" that consists of weeklong visits to four world regions for programs designed to address a topic important to the area, and (c) a set of globally coordinated courses taught concurrently at each partner institution using parallel syllabi and virtual global project teams drawing students from each of the five participating institutions. Upon completing their course work, students receive both an MBA degree from their home institution and a OneMBA diploma or certificate issued jointly by the five participating institutions.

The alliance is coordinated by an administrative group comprised of at least one faculty and one senior staff member (assistant or associate deans) as well as program managers or directors from each of the five partner institutions. This group formulates the strategic direction of the program, develops the curriculum and program infrastructure, and over- 
sees the management of the joint activities. It also makes decisions about joint marketing, program structure and offerings, and financial issues affecting the partnership.

In addition to the executive committee, OneMBA has four technical teams - marketing, logistics, admissions, and technology — which coordinate activities in these areas. The logistics and admissions teams are composed primarily of executive committee members. The marketing and technology teams draw from the relevant area experts in the partner schools. In addition, there are cross-institution working groups for each of the globally coordinated courses. Led by a faculty coordinator, each working group has created a common syllabus and identified common readings and case studies. They jointly oversee the global virtual teams across their courses and collaboratively grade team projects.

Each partner remains responsible for certain activities. For example, institutions determine their own admissions criteria and processes, though suggested guidelines have been set by the executive committee. Each school conducts its own orientation prior to a joint opening week. The institutions recruit their own faculty members to teach courses and negotiate compensation rates. Finally, each partner develops and offers its own portion of the curriculum through the regional courses.

\section{Great Plains IDEA}

In the mid-1990s, the Colleges of Human Sciences (sometimes called Colleges of Human Ecology) at 10 western and midwestern universities (Colorado State University, Iowa State University, Kansas State University, Michigan State University, Montana State University, University of Nebraska, North Dakota State University, Oklahoma State University, South Dakota State University, and Texas Tech University) established the Great Plains Interactive Distance Education Alliance (Great Plains IDEA) in order to develop cost-neutral distance education graduate programs in fields in which individual partners did not offer degrees because they lacked the complete content expertise to offer a full program. In 2001, a subset of the Great Plains IDEA institutions-Kansas State University, Montana State University, Iowa State University, South Dakota State University, North Dakota State University, Oklahoma State University, and the University of Nebraska-began offering an online master's degree in family financial planning. The alliance is developing additional graduate degree and certificate programs in gerontology, youth development, and merchandising. Students enroll in an alliance program through one of the partner institutions. All students, regardless of home institution, pay a common price for these courses. The partners have created an income-sharing formula that distributes income in three 
ways: (a) to the institution teaching a given course, (b) to the student's home institution for program contributions and student services, and (c) to the Great Plains IDEA for program coordination and joint activities such as marketing and maintaining its Web site. Students graduate with a degree from their home institution.

An executive board composed of one member from each partner institution coordinates the alliance. The board has an elected chair and is largely comprised of assistant or associate deans from the partner schools, though some faculty, deans, and department chairs have been selected by their institutions to represent their interests. The meetings rotate among partner institutions or are held in conjunction with other national professional meetings.

In addition to the leadership and coordination provided by the executive board, the alliance designates one partner as the "Lead Institution." The Lead Institution is responsible for managing the alliance's finances, including collecting and expending funds and maintaining correct and complete books and records of accounts, and it assumes a leadership role in coordinating alliance activities.

Each partner institution can decide the programs in which it would like to teach and offer degrees and/or certificates. Any partner institution can propose a degree program, though it must take the lead in gaining program approval from the alliance. Within each Great Plains IDEA program, faculty from participating institutions work together to design the curriculum and develop courses. Each institution also develops the corresponding employment and compensation agreements under which its faculty teach Great Plains IDEA courses. Institutions also are responsible for admitting, advising, and working with enrolled students. They field questions from prospective students, maintain student records, uphold university policy, and conduct graduation audits.

\section{The Rules Essential to Key Alliance Tasks}

The following discussion outlines the most prominent adaptive rules that emerged from our examination of these CJVs. We present the findings through an emergent framework grounded in the realities of creating and managing alliances. This is appropriate since the phenomena of academic alliances have not been sufficiently studied. In the analysis that follows we point to clearly discernible patterns of rule creation to negotiate different organizational cultures by these CJVs in each of these areas. The chief issues regarding the coordination of these CJVs were (a) identifying partners, (b) developing and delivering the curriculum, (c) making operational decisions and resolving emergent conflicts, 
and (d) balancing individual and collective partner interests. These activities closely mirror the key issues in private-sector strategic alliances of (a) managing coordinated operations (Borys \& Jemison, 1989; Gulati \& Singh, 1998; Rondinelli \& London, 2001), (b) determining partner investments in the alliance and dividing returns (Spekman, Forbes, Isabella, \& MacAvoy, 1998; Ring \& Van de Ven, 1994), and (c) demarcating boundaries between alliance and partner responsibilities (Borys \& Jemison, 1989).

\section{Finding Partners}

The first task of any joint venture is finding a suitable partner (or partners) with which to work. The CJVs in the study were guided by selection rules largely based on shared values rather than maximizing return on investment.

A key characteristic of desirable partners was shared ambitions. Virginia Tech and Wake Forest discovered an immediate affinity because both aspired to become "players" in the fierce competition for NIH dollars. This ambition influenced the development of further rules such as the "cluster hiring" of faculty. While cluster hiring had obvious utilitarian value-creating a critical mass of researchers in key strategic areas-it also was intended to send a signal to external constituents (e.g., foundations) and competitors that the program was a national contender. As one administrator noted, cluster hiring is an effective strategy for "gaining national prominence really quickly."

The OneMBA program reflected the shared desire of participating partners to offer a truly international MBA with an international experience. Julie Yu of the Chinese University of Hong Kong enthused,

The Chinese University's MBA programs are focused upon four core values: globalization, relevance, innovation, and quality. OneMBA is the first program offered by CUHK which truly captures the spirit of globalization in today's dynamic world. The global residencies demonstrate best business practices in both developed and emerging economies. During these weeklong experiential trips, executive participants can directly draw from the concepts that have been discussed in the globally coordinated courses immediately preceding the residencies. Innovation and quality are clearly demonstrated in this premier global executive MBA program. It is obvious that our core values are very well expressed in this particular program, so the OneMBA is a great fit for us. Shared values and cultural norms proved important for establishing compatibility.

Wake Forest and Virginia Tech are vastly different institutions. One is a private, liberal arts institution with a medical school, and the other is a public polytechnic institute with a renowned engineering program. Nevertheless, both have an intensely entrepreneurial ethos, as evidenced by 
their track record of innovative practices. For example, Virginia Tech took the lead in a remarkable venture that created a public veterinary school supported jointly by Virginia and Maryland. It also launched a business incubator and created a partnership with an area hospital. Wake Forest's president had promoted greater interdisciplinary teaching and research. This shared commitment to innovation was in evidence at an early meeting between the leadership of the two institutions. A Wake Forest faculty member who attended recalled his president saying: "In the future there will be 30 to 50 big time research institutions in this country. We're going to be one of them and these places will be defined by their strategic alliances. That's why we are committed to doing this program."

For OneMBA, all of the partners greatly valued institutional excellence (reflected, e.g., in external rankings). Said one UNC faculty member, "We don't just want any partner; we want the top-notch partner. We want somebody who is considered a leader in its region." They also found partners who shared the same philosophical beliefs about graduate business education. Said Penny Oslund of UNC,

I think it is very important that you share similar philosophies. I think that we have been able to avoid a lot of hurdles because of that. . . [W] had looked at [prospective partners'] curriculums very carefully. We knew that we were pretty much on the same page with what we felt should be offered. Our dean at the time had a colleague in Japan. We spent part of a day with him. The programs were so different! Theirs was like an eight- or ninemonth program and it just never would have worked. There obviously needs to be a sort of [common] foundation on which to build.

A key strategy identifying institutions with similar sets of values and priorities was tapping established professional or personal networks. For example, four of the OneMBA partners had already known one another and had pursued opportunities to collaborate with one another in the past. At the time of its formation, Chinese University of Hong Kong chose a dean who was a former doctoral advisee of UNC's dean, Robert Sullivan, who in turn had helped EGADE establish its doctoral program. The key faculty member at EGADE, Alejandro Reulas-Gossi, was a UNC graduate, and the Brazilian institution FGV and UNC had collaborated on undergraduate programs. The principals of Great Plains IDEA also had long-standing relationships with one another through various midwestern professional and scholarly meetings. As Marjorie Kostelnik, the dean at the University of Nebraska, observed: "You have to know your partners. You can't just walk in randomly and say let's take these ten schools. ... You have to have some history, or at least some members that have history. . . . You don't just look them up in the phone book." 
Similarly, faculty members at Virginia Tech and Wake Forest knew one another because of their professional connections in the biomedical field. In fact, it was collegial interaction between faculty members from both institutions at a meeting that spurred the early discussions that led to the joint program.

It is worth noting that none of these institutions used a set of maximizing criteria to determine their ideal partner. There clearly was a recognition that a partnership would strengthen the relative position of the individual institutions or even compensate for a strategic weakness (as was the case with SBES, where the expertise of both institutions was necessary to create a biomedical engineering program). However, cold calculations like the assessment of market potential of the partnership or weighing the potential strengths and weaknesses of one prospective partner against another simply did not occur. Instead, the rules shaping partnership formation focused on identifying shared values as a basis for a common identity and made use of existing personal relationships.

\section{Curriculum and Instruction}

Rules for governing curriculum and instruction-what is taught and by whom-are perhaps the most central for any academic enterprise. Each CJV faced the task of developing mutually acceptable academic programs. One rule that emerged in all three cases was that no program would be offered without the full support of all parties. However, how quickly consensus emerged for the curriculum varied among the study sites.

For example, the partners in OneMBA had no trouble finding common ground on their curriculum since all held that an excellent MBA program had four fundamental building blocks - sourcing, selling, managing, and competing. Nonetheless, putting such a curriculum into place was complicated by another espoused alliance imperative, "making the program marketable in each region." As Mike Page from the Rotterdam School of Management explained, "The first sense was the recognition that we wanted to emphasize the global, but we didn't want to detract from the local and regional." To balance the global continuity of OneMBA with local curricular needs, the CJV established an additional rule granting each partner a degree of flexibility to develop a subset of courses exclusive for local students. Thus, Chinese University of Hong Kong offered a course on trade in China, and the Brazilian partner taught a course on social responsibility.

By contrast, Great Plains IDEA lacked any discipline-specific standard of value because their offerings were broad. To ensure curricular common ground they devised a process for making decisions about each 
proposed program. Each was presented to the executive committee in the form of a concept paper that outlined the need for the program, the potential roles of the various partners, a detailed time line for implementation, and a financial plan. This ensured that all programs pursued were consonant with the expectations, priorities, and values of each partner.

\section{Resolving Administrative Conflicts and Seeking Compromise}

CJVs face a host of administrative decisions as well. To address these, each site adopted processes that were largely characterized by discussion, debate, and consensus. The CJVs did not vote in order to resolve deadlocks, choosing instead to grapple with the problem and devise potential alternatives until each partner was satisfied. Vicki Jones, associate dean for international relations at FGV, said about OneMBA, "We make decisions by discussion and consensus. We look at pros and cons. ... We were very conscious as to what the outcome would be regarding the quality of the program for our students."

This approach had important positive consequences when misunderstandings occurred. Occasionally, OneMBA participants came into conflict because of their distinct international identities and the disparate cultural expectations of the partners. David Ravenscraft of UNC observed,

I was always surprised at where we got stuck. We had the attitude that we were not going to move on until we resolved the tough issue. It was fine to talk about something else, but the group kept coming back to resolve the difficult issue. We often had to take a lot of breaks to discuss things in the halls. This is where the cultural differences really rise. For example, some Asians don't like to argue in public. We were blessed with partners from each institution that understood the U.S. and could educate the group into the right approach and let us know when we made cultural mistakes. We had the right chemistry among the people; that really helps.

\section{Balancing Collective and Individual Partner Interests}

A partnership is built on mutual concern but must also account for individual partner priorities and preferences. The agreement of OneMBA that the program must "be marketable in each region" proved a challenging one to accommodate. Beyond allowing for the offering of locally specific courses, OneMBA also had to reconcile disparate expectations about program design. The Americans argued that MBA programs lasting less than 16 months are generally viewed as substandard in the United States and that global residencies could be no longer than two weeks for busy American executives. The others finally agreed to accommodate this request. The executive committee of OneMBA also 
found it important to ask the extent to which a particular decision is what they labeled as "core or peripheral" to the CJV's operation. The former became joint decisions, and the latter were left to individual partners. To make these distinctions they negotiated among themselves. Vicki Jones of FGV said,

Is it core or peripheral how many pages an assignment is? Is it core or peripheral that the assignment has to involve original research in every region? Is it core or peripheral how often the faculty meet or that the faculty make a certain amount of their decisions together? When we make decisions, determining what is core and peripheral really helps determine where we put our efforts. We don't always agree on what is core or peripheral; [however,] once we define that, the other decisions become much easier. It keeps us from micromanaging, from chasing clouds, and it allows us to direct energies into what are core for our students.

Great Plains IDEA adopted the rule that when differences emerged on matters of specific policy, the partners would adopt the most stringent existing campus policy. For example, one institution required 36 hours for a master's degree while another required only 30 hours. They therefore adopted the 36-hour standard. As one administrator explained, "We decided to use the most difficult, the most constraining, the most challenging set of rules. ... Otherwise there would be people who say, 'I can't compromise on this' and when you don't have any room to compromise alliances fall apart." Such a rule had the twin virtues of underscoring the collective commitment to quality and ensuring that no partner would later be haunted by concerns about making undue compromises.

The CJVs developed other rules aimed at strengthening the collective while upholding the values and interests of individual partners. For example, Great Plains IDEA decided to (a) not offer programs that would directly compete with the current offerings of individual partners, (b) focus on finding those areas in which various institutions had insufficient depth to offer complete programs on their own, and (c) seek to establish intellectual homes for faculty who felt isolated on a particular campus. For example, the alliance devised programs such as family financial planning and fashion merchandising, because the partners collectively had enough faculty members working in related areas to mount a degree program but none could do it alone.

New interpretations of existing policies were established by SBES in order to promote mutual collaboration. Since the school was an interdisciplinary effort (not only between Virginia Tech and Wake Forest but also among departments within each institution), a key alteration occurred in the way that the institutions assigned credit for teaching 
and research activity. At both institutions, departmental success was determined by credits taught and research dollars secured: But how would they account for coteaching or joint research? Ultimately, a policy of "double-counting" was established. Thus, if two faculty members from different schools worked together to secure a research grant, both departments were given permission to "count" that grant money in its annual report to the provost and both were credited for that success.

Institutions also created financial structures that, although different, allowed them to balance their collective and individual needs. For example, Great Plains IDEA thought it important that students pay a common price for all Great Plains IDEA courses $(\$ 350$ per credit hour for 2003-04), regardless of the tuition and fees of the teaching institution. It wanted a fair system, one where no institution could underprice another. It also created a revenue-sharing formula: $12.5 \%$ to admitting/home university (where the student enrolls to cover student services and registrar functions), $12.5 \%$ to the alliance to support joint activities, and $75 \%$ to the teaching university (for instructional and associated costs). In contrast, rather than avoiding competitive advantage issues within the alliance like Great Plains IDEA, OneMBA adopted financial rules that gave the partners flexibility to set their own pricing in order to compete vigorously in their local MBA markets. Students pay the tuition set by the institution through which they enroll. Each institution identified a price that its own market would bear, not one that would be common (or "fair" to use a rule from Great Plains IDEA) to all students. This helped individual alliance members compete in their own markets and set pricing at a level to meet their individual financial objectives.

\section{Discussion}

The experiences of these three CJVs reveal much about how mutually beneficial curricular partnerships are formed and renegotiated despite their inevitable differences in institutional policies, practices, and values. Below we offer five propositions that we believe illuminate the central challenge of these partnerships - the reconciliation of disparate organizational cultures.

P1: By selecting familiar partners who have common ambitions and objectives rather than partners that might maximize a particular outcome, institutions establish a set of shared values that allows for easier reconciliation of disruptive differences.

The management literature on strategic alliances underscores that the best partners are those with similar strategic goals (Dussauge \& 
Garrette, 1999). One would therefore imagine that the sensible approach to partner selection would be to research scrupulously the strategic aims of prospective partners and determine their capacity for maximum contribution to the shared aim. Quite the contrary, these CJVs looked to partners where there was a natural affinity first. Only after that did partners attempt to determine if they had common objectives. Although this may appear to be the enactment of a "satisficing" process in which institutions expend just enough energy to find a partner that meets a basic criteria (i.e., one that is "good enough") as compared to a maximizing set of criteria (March, 1994), there are good reasons why, as in a human courtship, shared interests and similar social networks often trump cold economic calculation. Familiarity aids in identifying partners' similar sets of norms and values (and conversely assists in weeding out potential misfits during the preselection process). This is critically important because a drastic misalignment of expectations in any number of key areas-curricular structure, teaching quality, or collaboration on research-is likely to result in gridlock and may terminate the partnership.

P2: Recognizing the inherent tensions between the interests of the individual partners and the collective was a key factor influencing organizational resilience and stability.

Members of alliances find basic institutional processes such as planning, developing protocols, setting policy, and even the formation of working objectives to be familiar activities. Inevitably, partnerships engender certain tensions. The most fundamental is determining which activities are being conducted on behalf of the alliance and which are intended to serve the particular partner. Put another way, when may we act as individuals and when must we confer for the benefit of the collective? For these CJVs, a commitment to surfacing and addressing these tensions was a key factor in their ongoing viability.

Time was dedicated by OneMBA to defining activities that were "core" to the CJV and those that were "peripheral"; the question became a veritable mantra. Great Plains IDEA struggled over whether each member could determine which faculty would be assigned to its programs. Such tensions were not always easily resolved. As SBES's associate director observed when describing the potentially contentious process of space allocation:

I just said [to my counterpart] just do it and here's what's going to happen. You're going to have $80 \%$ of it right and $20 \%$ of it I'm not going to agree with either because it's wrong or because I didn't explain myself properly. Let's just face it and deal with it, we're not going to be angry with each other. It's nothing personal. 
In sum, resolution of these issues required open deliberation (and a sense of equanimity) that engendered shared understandings rather than the rote operationalization of predetermined collective preference (Cohen \& March, 1986).

P3: Effective partnerships require a personal commitment built on ongoing face-to-face interaction rather than watertight policies and procedures.

The processes of developing the coordination rules we describe above almost exclusively occurred through face-to-face interactions. All of the CJVs held regular meetings that provided a forum for debating issues, raising difficult questions, and challenging assumptions. These meetings tended to be held more frequently during the formational stages of the CJV. Arranging such meetings was no simple task and involved the crossing of state lines and, in the case of OneMBA, dealing with national borders and numerous time zones. An administrator from Kansas State noted about Great Plains IDEA, "Almost every challenge and barrier has been solved through interpersonal face-to-face interaction and brainstorming and getting really smart people in the same room focused on resolving the problem."

Although the experiences of these CJVs underscore the importance of establishing clear guidelines, their effective operation intimately relied on their capacity to establish professional and personal relationships grounded in mutual trust and a shared sense of purpose. Unlike their counterparts in many corporate environments, where behavior can be dictated or at least directed from above, academics, given their professional authority, cannot be told what to do (Mintzberg, 1993). Thus, relationships, not organizational hierarchy, become the glue that holds alliances together. For instance, SBES's oversight committee, which is comprised of faculty and senior administrators from each institution, was initially established to administer the program. However, over time a vitally important purpose has emerged. As one senior faculty member remarked, "There's a sense of community about it." Although the committee does not meet frequently, its key members are in touch with one another regularly, particularly the director of SBES (a Virginia Tech faculty member) and the associate director (from Wake Forest). One administrator contrasted SBES with another existing partnership: "That one is very contractual, to the point where on every issue we have a separate memorandum and agreement. There isn't that level of trust yet. SBES is a true partnership." Ultimately, a complex partnership cannot depend on the manufacturing of a list of guidelines and rigid adherence to formal rules. What matters instead seems to be the emergence of commonly accepted values and a sense that the individual institutions are as intent on paying attention to the well-being of one another as they are for themselves. 
P4: The more alliances are able to create a shared identity, the greater a chance that conflict will be diminished.

As we began this study, we anticipated conflict and difficulty between partners. The management literature on alliances points to the prodigious difficulties of merging the activities of institutions with their own cultures and habits. Further, it is widely recognized that faculty and administrators (both key participants in these alliances) can be at odds with one another on a single campus, let alone when multiple institutions are involved. In fact, this was not the case. In general, the conflicts that occurred within and between partner institutions were relatively minimal. A key mediating factor was the presence of preexisting shared values, especially shared disciplinary norms.

Each CJV found it vitally important to begin by establishing clear guidelines for the partnership. This involved the manufacturing of and steadfast adherence to technical rules. Of course, when faced with unfamiliar and challenging situations, the rules could not cover every contingency. Although it would not have been possible for SBES to pass the State Council in Virginia without a clearly articulated agreement, decisions have increasingly come to be guided more by a collective sense of appropriateness than by slavish reliance on a policy manual. As one participant noted, "We had an attorney go through everything but in the end, you know, I think what matters is trust-very quickly we have come to trust one another and to see things in the same way. We know what we mean by the agreement, the spirit of it."

This ability to intuit the "spirit" of the agreement reflects a shared sense of purpose derived from a common, joint identity. The joint efforts surface challenges that technical rules cannot address; thus the shared identity serves as a common platform to explore possible appropriate rules (March, 1994).

Sometimes institutional cultures were a source of shared values. Members of OneMBA had a shared commitment to entrepreneurialism and prized prestige. There were also disciplinary bonds. The principals of OneMBA all had a common business-scholar background. It is perhaps no surprise that they ended up with a very short set of formal rules. Similarly, the core faculty members at SBES had a shared understanding of what an exemplary biomedical engineering program ought to look like. In both of these instances, participants already "knew" what curriculum to offer, what ideas students should be exposed to, how they ought to coordinate various curricular activities, and so forth. A quotation from Julie Yu at OneMBA describing the easy agreement on the basic curricular elements of its program is instructive. She said, "Any [MBA] program in the world has to have those basic functional courses 
[leadership and organizational behavior, operations, marketing, finance, and strategy]." One might say that everyone involved knew not only the music and the words but also the dance steps.

In the absence of a preexisting set of organizational and disciplinary values, the formation of a common identity proved harder to cultivate. Great Plains IDEA retained its thick handbook specifying a long list of policies and procedures. (Indeed, the CJV had rules about how rules could be proposed and adopted as well as rules as to who was the keeper of the rules as codified in the alliance handbook.) Great Plains IDEA's principals never developed a strong common identity. Although each was associated with a similar college with a shared land-grant mission, the participants had different disciplinary backgrounds and held different positions in their respective institutions. One might argue that Great Plains IDEA had more rules simply because it was a more complex alliance, offering more programs and involving more institutions. However, it is also the case that the very nature of those rules and the degree to which various procedures were spelled out were qualitatively different from SBES and OneMBA. The larger size of the CJV and the absence of shared disciplinary norms and values made forming a common identity more difficult. Instead of being able to draw upon shared identities to make decisions, the partners had to rely on more formal processes.

\section{Conclusion}

The central finding of this study is that paying attention to the relational aspects of partnership development and maintenance is at least as important, if not more important, as developing curricula, determining financial structures, managing operations, and expanding enrollments and research dollars. In sharp contrast, the management literature tends to focus on the operational aspects of alliances. The most salient question regarding academic alliances is not how do we organize ourselves to get the job done more effectively but who are we and how do we figure out how to work well with one another. Against much of the corporate IOR literature, this study suggests that curricular alliances significantly depend on establishing a set of principles grounded in a common academic culture. Forging relationships and forming a shared identity should rightfully demand more attention than the identification of alliance objectives or procedures.

This study offers a different assessment of the notion of finding the "right" partners. It seems that the most valuable elements regarding finding partners is to identify those with whom one is familiar, has com- 
mon objectives, and, most important, has a likelihood of developing a shared identity. The CJVs in this study did not hunt for partners that would allow them to deliver the best program and then invest time and energy in creating mechanisms to work together. Instead, they found partners that were good enough on a technical level, but with whom they connected strongly. This type of "satisficing" is notably absent in the corporate alliances described in the literature. One important difference between the corporate sector and the academic one is that colleges and universities have little organizational slack to innovate. This fact might suggest that because they lack the resources to invest broadly in innovation, any useful activity with a trusted partner is worth considering. Another possibility is that institutions do not have the resources to look for the maximizing partner and instead turn to those familiar and trusted. A final explanation is that they may be able to avoid expenses associated with the relationship and, instead, can invest in the operations. The more shared the identity the less reliance on formal rules and the easier it is to respond to adaptive challenges for which there is no history or script and thus less cost. Finding ways to minimize the number of formal rules seemed to simplify collaboration, and having a common identity contributed to this.

While this research provides important insight to this inadequately studied phenomenon, it leaves many questions unanswered. In some cases, the limited sample suggests additional research across institutional types and involving different types of CJVs. Additionally, some specific questions exist regarding alliances at research universities. For example, does unique identity always lead to success, by what metrics? What obstacles can impede success in the face of good intention to develop and nurture a shared sense of identity? Can certain "showstoppers" derail identity as the important glue? Do other instances exist when identity is not significant? Can another type of commitment or characteristics replace shared identity? These questions, and others, deserve further investigation.

\section{Notes}

${ }^{1}$ CJVs have a superficial similarity to traditional $2+3$ programs where, for example, a student at a small liberal arts college might take some foundational course work for two years but transfer to a university to complete an engineering degree. However, such arrangements are largely concerned with making efficient use of existing resources rather than strategically creating new programs. Further, the university is not dependent upon the liberal arts college and could readily continue the program on its own.

2It should be noted that some espoused values, particularly lofty ideals, may be aspirational and not always perfectly mirrored in organizational behavior. 


\section{References}

Bailey, D., \& McNally Koney, K. (2000). Strategic alliances among health and human services organizations: From affiliations to consolidations. Thousand Oaks, CA: Sage.

Barringer, B. R., \& Harrison, J. S. (2000). Walking a tightrope: Creating value through interorganizational relationships. Journal of Management, 26(3), 367-403.

Borys, B., \& Jemison, D. B. (1989). Hybrid arrangements as strategic alliances: Theoretical issues in organizational combinations. Academy of Management Review, 14, 234-249.

Burns, T. R., \& Flam, H. (1987). The shaping of social organizations: Social rule system theory with applications. Beverly Hills, CA: Sage.

Cohen, M. D., \& March, J. G. (1986). Leadership and ambiguity: The American college president (2nd ed.). Boston: Harvard Business School Press.

Deal, T. E., \& Kennedy, A. A. (1982). Corporate cultures: The rights and rituals of corporate life. Reading, MA: Addison-Wesley.

Dotolo, L. G., \& Strandness, J. T. (Eds.) (1999). Best practices in higher education consortia: How institutions can work together. New directions for higher education, No. 106. San Francisco: Jossey-Bass.

Doz, Y. L. (1996). The evolution of cooperation in strategic alliances: Initial conditions or learning processes? Strategic Management Journal, 17, 55-83.

Dussauge, P., \& Garrette, B. (1999). Cooperative strategy: Competing successfully through strategic alliances. New York: Wiley.

Eckel, P. D. (2003). Changing course: Making the hard decisions to eliminate academic programs. Westport, CT: Praeger.

Eckel, P. D., Hartley, M., \& Affolter-Caine, B. (2004). Cooperating to compete: A campus leaders' guide to developing curricular partnerships and joint programs. Washington, DC: American Council on Education.

Glaser, B., \& Strauss, A. (1967). The discovery of grounded theory. Chicago: Aldine.

Gulati, R., \& Singh, H. (1998). The architecture of cooperation: Managing coordination costs and appropriation concerns in strategic alliances. Administrative Science Quarterly, 43, 781-814.

Hagadoorn, J. (1993). Understanding the rationale of strategic partnering: Interorganizational modes of cooperation and sectoral differences. Strategic Management Journal, 14, 371-385.

Hamel, G. (1996). Strategy as revolution. Harvard Business Review, July-August, 69-82.

Heifetz, R. A. (1994). Leadership without easy answers. Cambridge, MA: Harvard University Press.

Helms Mills, J. C., \& Mills, A. J. (2000). Rules, sensemaking, formative contexts, and discourse in the gendering of organizational culture. In N. M. Ashkanasy, C. P. M. Wilderom, \& M. F. Peterson (Eds.), Handbook of organizational culture and climate (pp. 55-70). Thousand Oaks, CA: Sage.

Herriott, R. E., \& Firestone, W. A. (1983). Multi-site qualitative policy research: Optimizing description and generalizability. Educational Researcher, 12, 14-19. 
Holstein, J., \& Gubrium, J. (1995). The active interview. Thousand Oaks, CA: Sage.

LeCompte, M. D., \& Preissle, J. (1993). Ethnography and qualitative design in educational research (2nd ed.). New York: Academic Press.

Lincoln, I., \& Guba, E. G. (1985). Naturalistic inquiry. Newbury Park, CA: Sage.

March, J. G. (1994). A primer on decision making: How decisions happen. New York: Free Press.

March, J. G., Schulz, M., \& Zhou, X. (2000). The dynamics of rules: Change in written organizational codes. Palo Alto, CA: Stanford University Press.

Martin, J., \& Samels, J. E. (2002, May 17). We were wrong; try partnerships, not mergers. Chronicle of Higher Education, p. B10.

Merriam S. B. (1988). Case study research in education: A qualitative approach. San Francisco: Jossey-Bass.

Miles, M. B., \& Huberman, A. M. (1994). Qualitative data analysis (2nd ed.). Thousand Oaks, CA: Sage.

Mills, A. J. (1988). Organization, gender and culture. Organization Studies, 9, 351-369.

Mintzberg, H. (1993). Structures in fives: Designing effective organizations. Englewood Cliffs, NJ: Prentice-Hall.

Oliver, C. (1990). Determinants of interorganizational relationships: Integration and future directions. Academy of Management Review, 15(2), 241-265.

Park, S. H., \& Russo, M. V. (1996). When competition eclipses cooperation: An event history analysis of joint venture failure. Management Science, 42(6), 875-890.

Patton, M. Q. (1990). Qualitative evaluation and research methods (2nd ed.). Newbury Park, CA: Sage.

Peterson, M., \& Spencer, M. G. (1991). Understanding academic culture and climate. In M. Peterson, E. E. Chaffee, and T. H. White (Eds.), ASHE reader on organization and goverance (pp. 140-155). Needham Heights, MA: Simon and Schuster.

Pettigrew, A. M. (1995). Longitudinal field research on change: Theory and practice. In G. P. Huber \& A. H. Van de Ven (Eds.), Longitudinal field research methods: Studying processes of organizational change (pp. 91-125). Thousand Oaks, CA: Sage.

Pfeffer, J., \& Salancik, G. R. (1978). External control of organizations: A resource dependence perspective. New York: Harper and Row.

Porter, M. (1996). What is strategy? Harvard Business Review, November-December, 61-78.

Ring, P. S., \& Van de Ven, A. H. (1994). Developmental processes of cooperative interorganizational relationships. Academy of Management Review, 19, 90-118.

Rondinelli, D. A., \& London, T. (2001). Partnering for sustainability: Managing nonprofit organization-corporate environmental alliances. Washington, DC: Aspen Institute.

Rubin, H. I., \& Rubin, I. S. (1995). Qualitative interviewing: The art of hearing data. Thousand Oaks, CA: Sage.

Saxton, T. (1997). The effects of partner and relationship characteristics on alliance outcomes. Academy of Management Journal, 40, 443-461.

Schein, E. H. (1992). Organizational culture and leadership (2nd ed.). San Francisco: Jossey-Bass. 
Spekman, R. E., Forbes, T. M., Isabella, L. A., \& MacAvoy, T. C. (1998). Alliance management: A view from the past and look to the future. Journal of Management Studies, 35(6), 747-772.

Van Maanen, J. (1979). The fact of fiction in organizational ethnography. Administrative Science Quarterly, 24, 539-550.

Whealler Johnson, S., \& Noftsinger, J. B. (2004, July/August). Getting a grip on strategic alliances. Trusteeship, 12(4), 15-19.

Whetten, D. A. (1981). Interorganizational relations: A review of the field. Journal of Higher Education, 52, 1-28.

Yin, R. K. (1994). Case study research: Design and methods. Thousand Oaks, CA: Sage. 
Copyright of Journal of Higher Education is the property of Ohio State University Press and its content may not be copied or emailed to multiple sites or posted to a listserv without the copyright holder's express written permission. However, users may print, download, or email articles for individual use. 